\title{
Functional Involvement of CD44 Variant 7 in Gut Immune Response
}

\author{
Bianca M. Wittig a Andreas Stallmach ${ }^{\text {b }}$ Martin Zeitz ${ }^{a}$ Ursula Günthertc \\ aMedical Clinic I, Benjamin Franklin University Hospital, Free University of Berlin, Berlin, and bMedical Clinic II, \\ University of Saarland, Homburg/Saar, Germany; CInstitute for Medical Microbiology, University of Basel, \\ Basel, Switzerland
}

\section{Key Words}

CD44 variant isoforms - Crohn's disease $\cdot$ Anti-CD44

variant therapy · Apoptosis induction

\begin{abstract}
A major problem in inflammatory bowel disease (IBD) is the accumulation of highly activated T-helper cells that are refractory to apoptosis induction. Hence, persistent inflammatory lesions are prevalent and are the basis of chronic disease. In IBD upregulation of costimulatory molecules on lamina propria lymphocytes has been described leading to apoptosis resistance. CD44 is a cell adhesion molecule and a signalling receptor that functions as a costimulatory molecule in T-cell activation. Several variant isoforms of CD44 (CD44v) are expressed by alternative splicing of variant exons encoding extracellular regions. Particularly isoforms containing CD44v7 are expressed on T cells and macrophages in T-helper-1 (Th1)-mediated chronic inflammation and autoimmune diseases. In this review recent data on the functional involvement of CD44V7 isoforms in IBD are discussed. In a mouse model of experimental colitis blockade or deletion of CD44v7 protects mice from severe intestinal inflammation by inducing apoptosis in lamina propria mononuclear cells. Recently, we observed that in lamina
\end{abstract}

propria mononuclear cells from the inflamed but not uninflamed mucosa of patients with Crohn's disease, blockade of CD44v7 isoforms also induces apoptosis. The finding that obstruction of CD44v7 isoforms can antagonize Th1-cytokine-dependent immune pathology identifies CD44v7 as a target in the treatment of inflammatory diseases such as IBD, rheumatoid arthritis, multiple sclerosis and other autoimmune diseases in which CD44V7 isoforms are upregulated.

Copyright $\odot 2003$ S. Karger AG, Base

\section{Introduction}

The mucosal immune system is comprised of anatomically defined lymphoid microcompartments, such as Peyer's patches in the small intestine, appendix, and solitary follicles in the large intestine and rectum, nasal mucosa and tonsils, which serve as principal mucosal inductive sites where immune responses are initiated. It also contains diffuse accumulations of large numbers of lymphoid cells that are either distributed in the lamina propria or interspersed among epithelial cells in mucosal tissues and glands, and form the effector sites where immune responses are expressed [1,2]. Three major adaptive effector mechanisms participate in the immune

\begin{tabular}{ll}
\hline KARGER & @ 2003 S. Karger AG, Basel \\
1015-2008/03/0703-0184\$19.50/0 \\
$\begin{array}{l}\text { Fax +4161306 12 34 } \\
\text { www.karger.com }\end{array}$ & $\begin{array}{l}\text { Accessible online at: } \\
\text { www.karger.com/pat }\end{array}$
\end{tabular}

Bianca M. Wittig

Medizinische Klinik I, Universitätsklinikum Benjamin-Franklin

Freie Universität, Hindenburgdamm 30

D-12200 Berlin (Germany)

Tel. +49 308445 4316, Fax +49 308445 4481, E-Mail bianca.wittig@medizin.fu-berlin.de 
defense of mucosal surfaces. Secretory IgA antibody formation and antigen-specific cell-mediated cytotoxicity are the primary mechanisms involved in antimicrobial defense in the mucosal epithelium. The induction of IgA production to protein antigens is highly dependent on Thelper cells $[3,4]$. In addition, mainly through the production of regulatory cytokines, regulatory $\mathrm{T}$ cells contribute as a third form of mucosal defense. The tissue microenvironment, the cytokine milieu and the antigen itself influence the further differentiation of $\mathrm{CD} 4+$ naîve $\mathrm{T}$ cells to T-helper (Th)-0 cells that produce both interferon (IFN)- $\gamma$ and interleukin (IL)-4 and further to a Th1- or Th2-directed immune response. Mucosal uptake of antigens may result in the development of immunity or tolerance, or even both, the decision being taken in the epithelium or underlying lymphoid tissue and it is mainly determined by the nature and presentation of the antigen. Besides the strength of the T-cell receptor signal or antigen density, the second signal in T-cell activation is provided by engagement of one or more T-cell surface receptors with their ligands on antigen-presenting cells. At present, the role of these pairs of costimulatory molecules, like CD28-B7 and CD154-CD40, in regulating Th1 versus Th2 immune responses in vivo is not known in detail [5].

\section{CD44 as a Cell Adhesion Molecule and a Signalling Receptor}

One of the lymphocyte markers which is supposed to work as a costimulatory molecule is the transmembrane glycoprotein CD44. The role of CD44 as a hyaluronan receptor has been known for many years and defines CD44 as a cell adhesion molecule [6]. However, there is also substantial evidence that CD44 is a potent signalling receptor. Early studies using anti-CD44 monoclonal antibodies to trigger the receptor established that CD44 is a costimulatory molecule on T cells [7-10]. For example, stimulation through CD44 has been reported to enhance T-cell proliferation and IL-2 production independent of CD28 [7, 8, 10, 11]. Furthermore, it has been shown that ligation of the costimulatory molecule CD40 rapidly upregulates CD44 expression on T cells [11]. In addition to $\mathrm{T}$ cells, stimulation through CD44 enhances macrophage production of proinflammatory mediators, including IL-12, IL-1 $\beta$, and tumor necrosis factor- $\alpha$ (TNF- $\alpha$ ) $[12,13]$. In the last decade, it has been reported that antiCD44 antibodies have potent anti-inflammatory activity in vivo [14-16], most probably resulting from an anti- body-mediated (anti-panCD44 antibody IM7) shedding of CD44 from leukocytes, thus preventing cell recruitment and activation [17]. Although IM7 has been taken under consideration for clinical immunotherapy in autoimmune disease and cancer, recent data pointed out its harmful side effects, such as systemic shock [18].

Whereas the standard form of CD44 shows a broad expression on various cells of epithelial and hematopoietic origin, alternative splicing of at least ten exons, encoding variant extracellular regions, generates a large number of isoforms [19]. Expression of these so-called variant isoforms is strictly controlled [20] and confined to specific states of lymphocyte activation, hematopoiesis and tumor progression [21-24].

\section{Specific Expression of CD44 Variant Isoforms v6 and $v 7$ on Activated Lymphocytes}

In the mouse model for experimental colitis, it has been shown that isoforms containing CD44v6 and $\mathrm{v} 7$ are hardly expressed on resting lymphocytes in the spleen, lymph nodes, peripheral blood or Peyer's patches [21]. After in vitro stimulation via a T-cell mitogen or a nominal antigen, however, there was upregulation of CD44v6 and v7. Expression patterns of these splice variants defined the molecules as activation markers in gut-associated lymphoid tissue. Particularly at inflammatory sites on lamina propria lymphocytes CD44v6 and $\mathrm{v} 7$ isoforms are strongly upregulated. In addition, since CD44v6 and v7 expression during activation was transient, it was tempting to speculate that these two variant isoforms are functionally active in lymphocyte activation [25].

\section{Blockade of CD44 Variant Isoforms Cures Experimental Colitis in the Mouse}

In experimental colitis CD44v7 expression is upregulated on mononuclear cells of intestinal inflammatory lesions in Th1-polarized inflammation. Unlike in vitro stimulation, expression of CD44v7 was not transient, but persistent [26]. Based on these data, it was demonstrated that administration of a monoclonal antibody against CD44v7 [27], but not anti-CD44v6, cures most mice with 2,4,6-trinitrobenzene sulfonic acid (TNBS)-induced colitis. The colitis induced by the haptenizing agent TNBS has been described as Th1-cytokine-driven inflammation [28]. In this model after an initial increase in the Th1 cytokine IFN- $\gamma$, the therapeutic effect of anti-CD44v7 anti- 
body treatment was accompanied by an increased production of IL-10 and a decreased production of IL-12 in lamina propria lymphocytes as well as systemically [29]. Furthermore, co-administration of a neutralizing antibody to IL-10 (2A5.7) completely abrogated the therapeutic effect of anti-CD44v7 antibody in TNBS colitis, which indicates the central role of IL-10 in CD44v7 regulation. It has been suggested that the CD44v7-specific antibody functions by regulating an overshooting $\mathrm{Th} 1$ reaction in chronic inflammation [30].

\section{CD44v7 Is Essential for a Th1-Type Immune Response}

To further define the role of CD44v6 and $\mathrm{v} 7$ in colitis, mice bearing a targeted deletion of exons $v 6$ and $v 7$ of CD44 were generated without affecting the expression of the other exons. Under normal conditions, these mice have no altered phenotype or changes in the distribution of cell subpopulations in the lymphatic systems. Mice with TNBS-induced colitis are protected from severe inflammation and wasting disease by deletion of CD44v7 alone and v6/v7. Adoptive transfer of bone marrow cells clearly shows that expression of CD $44 \mathrm{v} 7$ on hematopoietic cells but not on intestinal epithelia is necessary to establish intestinal inflammation [26]. Moreover, crossing CD44v6/v7 mutants with IL-10-deleted mice, which develop chronic enterocolitis [31], is protective against experimental colitis for an observation period of more than 1 year [26].

Why and at which stage is the region encoded by CD44v6 and v7 important in intestinal inflammation? According to the expression profile and proliferation studies, CD44v7 functions as a costimulatory molecule and might be a receptor molecule on antigen-presenting cells for an as yet unidentified ligand. We have shown recently that CD44v7 is upregulated by CD40 ligation [32], which promotes clonal T-cell expansion, and delays activation-induced cell death [33-35]. The ability of CD40 ligation to modulate an immune response towards cell proliferation and apoptosis may depend on the availability of additional coreceptors or ligands that are transiently upregulated during T-cell activation, e.g. CD44v7. Most interestingly, analysis of cell death in the inflamed lesions revealed that mononuclear cells in the CD44v7and CD44v6/v7-deleted infiltrates had higher rates of apoptosis as compared to those from wild-type mice. The increase in apoptotic markers, measured as active caspase 3, p85 PARP, and TUNEL activity is restricted to in- flamed lesions in CD44v7 (and v6/v7) null mice, indicating that blockade of CD44v7 may be a highly specific therapeutic approach in inflammatory bowel disease [26]. Recent data in murine models of experimental autoimmune encephalomyelitis and rheumatoid arthritis unequivocally demonstrate that not the standard region of CD44, whose expression is unaffected by the mutation, but rather the region encoded by exon $\mathrm{v} 7$, is causally involved in autoimmune or chronic inflammation [for review see 36 ].

\section{Blockade of CD44v7 Induces A poptosis in Patients with Crohn's Disease}

In the pathogenesis of inflammatory bowel disease, such as Crohn's disease or ulcerative colitis, dysregulated CD4+ T-cell activation and proliferation in the intestinal mucosa is a key component [37]. Crohn's disease is characterized by a Th1-directed immune response with increased CD4+ T-cell production of IFN- $\gamma$ and activated macrophages that secret TNF- $\alpha$ and IL-12 [38]. Data obtained in animal models of experimental colitis and humans suggest that Crohn's disease can result from a defect in counter regulating the immune response, e.g. by TGF- $\beta$, to normal mucosal antigens, which initiates and/ or sustains chronic inflammation [39]. Although both CD44v6 and CD44v7 are upregulated upon mitogenic stimuli in vitro, we have found an increased expression of CD44v7 but not CD44v6 in the peripheral blood and inflamed mucosa of patients with Crohn's disease, but not ulcerative colitis $[32,40]$. Since deletion of CD44v7 protects mice from colitis by induction of apoptosis of activated $\mathrm{T}$ cells and macrophages, blockade of $\mathrm{CD} 44 \mathrm{v} 7$ might be a new approach to re-induce programmed cell death of activated cells in chronic inflammatory conditions in humans. Indeed, we demonstrate that in patients with Crohn's disease blockade of CD44v7 with a monoclonal antibody induces apoptosis in the lamina propria mononuclear cells of inflamed mucosa, but not in the non-inflamed mucosa of Crohn's disease or control tissue. This effect is not detected in the lamina propria of patients with active ulcerative colitis or acute diverticulitis. In addition, apoptosis induction is also obtained using a recombinant CD44 variant fusion protein containing CD44v7.

Finally, the apparent influence of CD44v7 on IL-10 production needs to be discussed further. We have described in the mouse model that IL-10 becomes significantly upregulated by curative treatment with anti- 
Fig. 1. A In the normal gut mucosa Peyer's patch lymphocytes express small levels of CD44v7. Antigen exposure induces oral tolerance, mediated by regulatory cytokines such as TGF- $\beta$ and apoptosis of effector cells. B In chronic inflammatory bowel disease costimulatory molecules such as CD40 and CD44 that give contra-apoptotic signals, are upregulated on lamina propria mononuclear cells sustaining the chronic inflammation in the gut. LPL = Lamina propria lymphocytes.

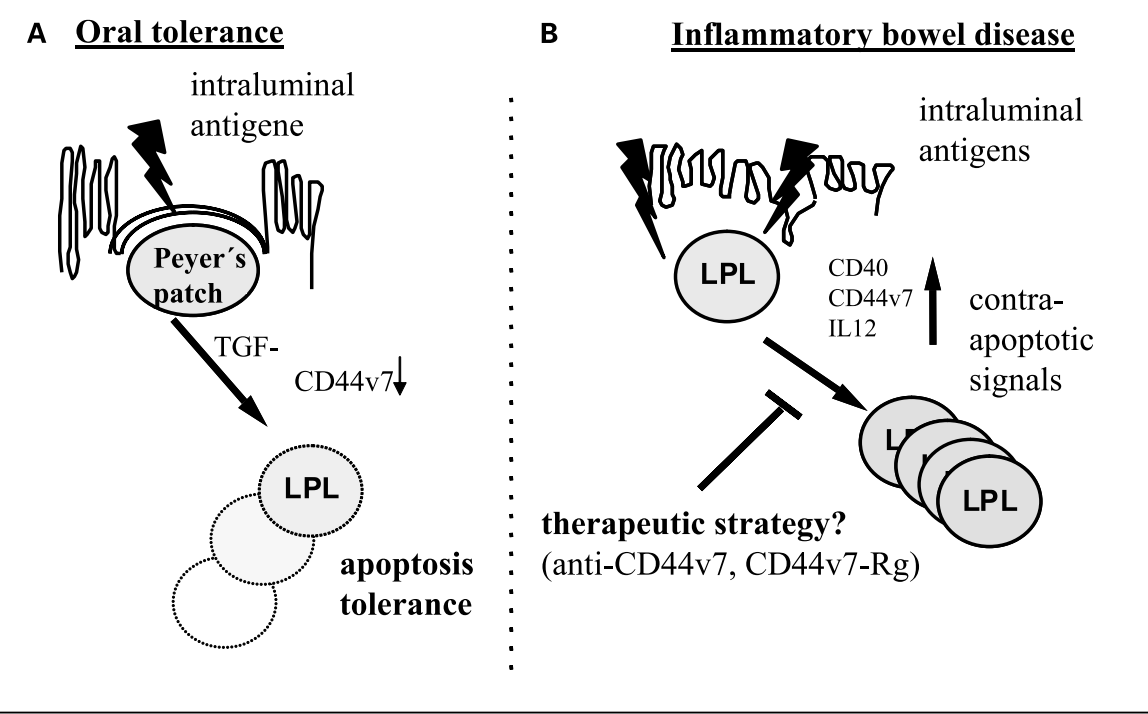

CD44v7 [29]. In a clinical study an increased number of IL-10-producing peripheral blood mononuclear cells in patients with inflammatory bowel disease has been described after in vitro culture with anti-CD44v7 [32]. Interestingly, anti-CD44v7-stimulated T cells as well as B cells and monocytes produce IL-10 [32]. In line with these findings, it has been described that Fas-mediated apoptosis of lymphoid cells leads to rapid production of antiinflammatory cytokines such as IL-10. In these studies, the apoptotic cells containing IL-10 were responsible for the activation of immune deviation through interaction with antigen-presenting cells [41, 42]. Thus, apoptotic cell death of immune effector cells and tolerance are linked through the production of an anti-inflammatory cytokine in order to minimize dysregulated immune reactions, e.g. a Th1-cytokine response that might compromise organ integrity $[43,44]$. Since apoptosis induction might restore immunological tolerance in intestinal mucosa, neutralizing CD44v7 might provide a promising therapeutic approach in inflammatory bowel disease (fig. 1).

\section{Conclusion}

The ubiquitously expressed CD44 standard molecule is the major cellular receptor for hyaluronic acid and a signalling receptor in T-cell activation. The present data on CD44 variant isoforms, which are expressed in a highly restricted manner, suggest a specific involvement of the variant isoform $\mathrm{CD} 44 \mathrm{v} 7$ in the gut immune system.
CD44v7 is essential for Th1-cytokine-mediated experimental colitis in distinct mouse models and upregulated in the inflamed mucosa in Crohn's disease. In the inflamed mucosa neutralization of the costimulatory molecule CD $44 v 7$ by a monoclonal antibody or a recombinant fusion protein induces apoptosis in human as well as mouse lamina propria mononuclear cells. Thus, CD44v7 appears to endow lamina propria mononuclear cells with resistance towards apoptosis leading to sustenance of the chronic inflammation in the gut. Many questions remain regarding the varied functions of the CD44 antigen, its multiple isoforms, and its multiple ligands. While hyaluronan polymers are components of the extracellular matrix and a substrate for CD44-mediated cell adhesion, hyaluronan fragments are signalling molecules which activate the immune system at the site of inflammation [45]. These hyaluronan fragments are themselves capable of activating NF- $\mathrm{KB}$ [46] and are present at abnormally high levels in chronic inflammatory conditions such as rheumatoid arthritis [47, 48]. Therefore, binding of matrix components via CD44 variant isoforms might mediate the specific activation signal in chronic inflammation [49]. Furthermore, proteolytic release of the CD44 intracellular domain may lead to direct influence of transcriptional activation of tumor-associated genes [50]. The role of CD44 in apoptosis is controversially discussed. Recent data indicate that deletion of the hyaluronan binding region induces prolonged inflammation in the lung by accumulation of hyaluronan fragments and decreased clearance of apoptotic neutrophils [51]. Others, however, 
have shown that binding of CD44 to hyaluronan generates an anti-apoptotic effect [52]. Also we have shown that $\mathrm{CD} 44 \mathrm{v} 7$ isoforms protect gut mononuclear cells from undergoing programmed cell death in chronic inflammation [26]. Differential regulation of cell activation and cell death via CD44 and its variant isoforms maybe the result of different ligand interactions, which may cause confor- mational changes. These changes will have an impact on the interaction with other surface molecules, which still need to be identified. Future therapeutic strategies may thereby include the exploitation of CD44 variant isoforms and the signalling by matrix components to directly induce apoptosis.

\section{References}

1 Brandtzaeg P, Farstad IN, Haraldsen G: Regional specialization in the mucosal immune system: Primed cells do not always home along the same track. Immunol Today 1999;6:267277.

2 Hein WR: Organization of mucosal lymphoid tissue. Curr Top Microbiol Immunol 1999;236: $1-14$.

3 Murray PD, McKenzie DT, Swain SL, Kagnoff MF: Interleukin 5 and interleukin 4 produced by Peyer's patch $\mathrm{T}$ cells selectively enhance immunoglobulin A expression. J Immunol 1987;148:2669-2674.

4 Kim PH, Kagnoff MF: Transforming growth factor-beta 1 is a costimulator for IgA production. J Immunol 1990;144:3411-3416.

5 Kishimoto K, Dong VM, Issazadeh S, et al: The role of CD154-CD40 versus CD28-B7 costimulatory pathways in regulating allogeneic Th1 and Th2 responses in vivo. J Clin Invest 2000;106:63-72.

6 Jalkanen S, Bargatze RF, Herron LR, Butcher EC: A lymphoid cell surface glycoprotein involved in endothelial cell recognition and lymphocyte homing in man. Eur J Immunol 1986; 16:1195-1202.

7 Huet S, Groux H, Caillou B, et al: CD44 contributes to $\mathrm{T}$ cell activation. J Immunol 1989; 143:798-804.

8 Shimizu Y, Van Seventer GA, Siraganian R, Wahl L, Shaw S: Dual role of the CD44 molecule in $\mathrm{T}$ cell adhesion and activation. $\mathrm{J}$ Immunol 1989;143:2457-2463.

9 Rothman BL, Blue ML, Kelley KA, et al: Human $\mathrm{T}$ cell activation by OKT3 is inhibited by a monoclonal antibody to CD44. J Immunol 1991;147:2493-2499.

10 Denning SM, Le PT, Singer KH, Haynes BF: Antibodies against the CD44 p80, lymphocytes homing receptor molecule augment human peripheral blood $\mathrm{T}$ cell activation. $\mathrm{J}$ Immunol 1990;144:7-15.

11 Guo Y, Wu Y, Shinde S, et al: Identification of a costimulatory molecule rapidly induced by CD40L as CD44H. J Exp Med 1996;184:955961.

12 Hodge-Dufour J, Noble P, Horton M, et al: Induction of IL-12 and chemokines by hyaluronan requires adhesion-dependent priming of resident but not elicited macrophages. J Immunol 1997;159:2492-2501.
13 Levesque MC, Haynes BF: TNF-a and IL-4 regulation of hyaluronan binding to monocyte CD44 involves posttranslational modification of CD44. Cell Immunol 1999;193:209-214.

14 Camp RL, Scheynius A, Johansson C, Puré E: CD44 is necessary for optimal contact allergic responses but is not required for normal leukocyte extravasation. J Exp Med 1993;178:497507.

15 Verdrengh M, Holmdahl R, Tarkowski A: Administration of antibodies to hyaluronan receptor (CD44) delays the start and ameliorates the severity of collagen II arthritis. Scand J Immunol 1995;42:353-358.

16 Mikecz K, Brennan FR, Kim JH, Glant TT: Anti-CD44 treatment abrogates tissue oedema and leukocyte infiltration in murine arthritis. Nat Med 1995;1:558-563.

17 McKee CM, Penno MB, Cowman M, Bao C, Noble PW: Hyaluronan (HA) fragments induce chemokine gene expression in alveolar macrophages. The role of HA size and CD44. J Clin Invest 1996;98:2403-2413.

18 Tanaka Y, Makiyama Y, Mitsui Y: Anti-CD44 monoclonal antibody (IM7) induces murine systemic shock mediated by platelet activating factor. J Autoimmun 2002;18:9-15.

19 Ponta H, Wainwright D, Herrlich P: The CD44 protein family. Int J Biochem Cell Biol 1998; 30:299-305.

20 König H, Ponta H, Herrlich P: Coupling of signal transduction to alternative pre-mRNA splicing by a composite splice regulator. EMBO J 1998;17:2904-2913.

21 Arch R, Wirth K, Hofmann M, et al: Participation in normal immune responses of a metastasis-inducing splice variant CD44. Science 1992;257:682-685.

22 Günthert U, Hofman M, Rudy S, et al: A new variant of glycoprotein CD44 confers metastatic potential to rat carcinoma cells. Cell 1991; 65:13-24.

23 Günthert U, Schwärzler C, Wittig B, et al: Functional involvement of CD44, a family of cell adhesion molecules, in immune response, tumor progression and haematopoesis. Adv Exp Med Biol 1998;451:43-49.

24 Stauder R, Günthert U: CD44 isoforms: Impact on lymphocyte activation and differentiation. Immunologist 1995;3:78-83.
25 Wittig B, Seiter S, Föger N, et al: Functional activity of murine CD44 variant isoforms in allergic and delayed type hypersensitivity. Immunol Lett 1997;57:217-223.

26 Wittig BM, Johansson B, Zöller M, Schwärzler $\mathrm{C}$, Günthert U: Abrogation of experimental colitis correlates with increased apoptosis in mice deficient for CD44v7. J Exp Med 2000; 191:2053-2063.

27 Schwärzler C, Oliferenko S, Günthert U: Variant isoforms of CD44 are required in early thymocyte development. Eur J Immunol 2001;10: 2997-3005.

28 Neurath M, Fuss I, Kelsall BL, Stüber E, Strober W: Antibodies to interleukin 12 abrogate established experimental colitis in mice. J Exp Med 1995;182:1281-1290.

29 Wittig B, Schwärzler C, Föhr N, Günthert U, Zöller M: Curative treatment of an experimentally induced colitis by a CD44 variant v7-specific antibody. J Immunol 1998;161:10691073.

30 Wittig BM, Zöller M, Zeitz M, Stallmach A: IL10 regulates the therapeutic effect of antiCD44v7 antibody in experimental colitis. Z Gastroenterol 1999;37:P164.

31 Kühn R, Löhler J, Rennick D, Rajewski K, Müller W: Interleukin-10-deficient mice develop chronic enterocolitis. Cell 1993;75:263274.

32 Wittig B, Seiter S, Schmidt DS, et al: Selective upregulation of CD44 variant isoforms on peripheral blood leukocytes in patients with chronic inflammatory bowel disease and other systemic autoimmune diseases. Lab Invest 1999;79:747-759.

33 Björck P, Banchereau J, Flores-Romo L: CD40 ligation counteracts Fas-induced apoptosis of human dendritic cells. Int Immunol 1997;9: 365-372.

34 Blair PJ, Riley JL, Harlan DM, et al: CD40 ligand (CD154) triggers a short-term $\mathrm{CD}+\mathrm{T}$ cell activation response that results in secretion of immunomodulatory cytokines and apoptosis. J Exp Med 2000;191:651-660.

35 Maxwell JR, Campbell JD, Kim CH, Vella AT: CD40 activation boosts $\mathrm{T}$ cell immunity in vivo by enhancing $\mathrm{T}$ cell clonal expansion and delaying peripheral $\mathrm{T}$ cell deletion. $\mathrm{J}$ Immunol 1999;162:2024-2034.

36 Günthert U, Johansson B: CD44 - A protein family involved in autoimmune diseases and apoptosis. Immunologist 2001;8:106-109. 
37 Zeitz M: Immunoregulatory abnormalities in inflammatory bowel disease. Eur J Gastrenterol Hepatol 1990;2:246-250.

38 Fuss IJ, Neurath N, Boirivant M, et al: Disparate $\mathrm{CD} 4+$ lamina propria lymphokine secretion profiles in inflammatory bowel disease. Crohn's disease LP cells manifest increased secretion of IFN-gamma, whereas ulcerative colitis LP cells manifest increased secretion of IL-5. J Immunol 1996;157:1261-1270.

39 Strober W, Ludviksson BR, Fuss IJ: The pathogenesis of mucosal inflammation in murine models of inflammatory bowel disease and Crohn's disease. Ann Intern Med 1998;128. 848-856.

40 Pfister K, Wittig BM, Mueller-Molaian I, et al: Decreased CD44v6 expression in lamina propria lymphocytes of patients with inflammatory bowel disease. Exp Mol Pathol 2001;71: 186-193.

41 Gao Y, Herndon JM, Zhang H, Griffith TS Ferguson TA: Anti-inflammatory effects of CD95 ligand (FasL)-induced apoptosis. J Exp Med 1998;188:887-896.
42 Nishigori C, Yarosh DB, Ullrich SE, et al: Evidence that DNA damage triggers interleukin 10 cytokine production in UV-irradiated murine keratinocytes. Proc Natl Acad Sci USA 1996; 93:10354-10359.

43 Schmidt M, Lügering N, Pauels HG, et al: IL10 induces apoptosis in human monocytes involving the CD95 receptor/ligand pathway. Eur J Immunol 2000;30:1769-1777.

44 Daigle I, Rückert B, Schnetzler G, Simon HU: Induction of the IL-10 gene via the Fas receptor in monocytes - An anti-inflammatory mechanism in the absence of apoptosis. Eur J Immunol 2000;30:2991-2997.

45 Aruffo A: CD44: One ligand, two functions. J Clin Invest 1996;98:2191-2192.

46 Noble PW, McKee CM, Cowman M, Shin H: Hyaluronan fragment activate an NF-kB/I-kBa autoregulatory loop in murine macrophages. $\mathbf{J}$ Exp Med 1996;183:2373-2378.

47 Poole A, Dieppe P: Biological markers in rheumatoid arthritis. Semin Arthritis Rheum 1994; 23S:17-31.
48 Bjermer L, Lundgren R, Hallgren R: Hyaluronan and type III procollagen peptide concentrations in bronchoalveolar lavage fluid in idiopathic pulmonary fibrosis. Thorax 1989; 44:126-131.

49 Chiu RK, Carpenito C, Dougherty ST, Hayes GM, Dougherty GJ: Identification and characterization of CD44RC, a novel alternatively spliced soluble CD44 isoform that can potentiate the hyaluronan binding activity of cell surface CD44. Neoplasia 1999;5:446-452.

50 Okamota I, Kawano Y, Murakami D, et al: Proteolytic release of CD44 intracellular domain and its role in the CD44 signaling pathway. J Cell Biol 2001;155:755-762.

51 Teder P, Vandivier RW, Jiang D, et al: Resolution of lung inflammation by CD44. Science 2002;296:155-158.

52 Lisignoli G, Grassi F, Zini N, et al: Anti-Fas induced apoptosis in chondrocytes reduced by hyaluronan. Arthritis Rheum 2001;44:18001807. 